\title{
ANALISIS STRATEGI PENGEMBANGAN AGROFORESTRI BERDASARKAN RANCANGAN TEKNIS IUPHKm DI DUSUN MELINANI, DESA MANUSELA, KABUPATEN MALUKU TENGAH
}

\section{ANALYSIS OF AGROFORESTRY DEVELOPMENT STRATEGY BASED ON IUPHKm TECHNICAL DESIGN IN MELINANI HAMLET, MANUSELA VILLAGE, CENTRAL MALUKU DISTRICT}

\author{
Nicolas. E. Patoding ${ }^{1)}$, John M. Matinahoru ${ }^{2)}$, Gun Mardiatmoko ${ }^{2)}$ \\ 1) Balai Perhutanan Sosial dan Kemitraan Lingkungan Wilayah Maluku-Papua \\ 2) Jurusan Kehutanan, Fakultas Pertanian, Universitas Pattimura \\ Penulis korespondensi e-mail: g.mardiatmoko@faperta.unpatti.c.id \\ \begin{tabular}{|l|l|}
\hline Diterima : 10 Juli 2017 & Disetujui : 2 Agustus 2017
\end{tabular}
}

\begin{abstract}
Intisari
Agroforestri adalah sistem penggunaan lahan yang bertujuan untuk mempertahankan atau meningkatkan hasil total secara berkelanjutan. Izin Pemanfaatan Hutan Rakyat (IUPHKm) merupakan izin usaha yang diberikan kepada kelompok masyarakat setempat untuk memanfaatkan hutan di kawasan hutan lindung dan atau kawasan hutan produksi. Manajemen HKm pada masyarakat di subdistrik Melinani dilaksanakan berdasarkan desain teknis agroforestri yang dibuat oleh BPSKL Wilayah Maluku dan Papua. Tujuan penelitian adalah: (1) Mengetahui karakteristik ekonomi, sosial dan budaya dan ekologi masyarakat Melinani dalam pemanfaatan Hkm; (2) Menentukan strategi dan prioritas pengembangan sistem agroforestri dan (3) Menganalisis faktor-faktor yang menentukan efektivitas kerja petani. Pada riset ini digunakan dan dilaksanakan analisis regresi berganda. Untuk penetapan strategi pengembangan agroforestry digunakan Analisis SWOT dan penetapan prioritas yang harus dilaksanakan menggunakan metode QSPM.Hasil analisis regresi menunjukkan bahwa tingkat pendidikan dan jarak dari tempat tinggal memiliki dampak pada pengembangan agroforestry. Analisis SWOT berada di kuadran I. Ini berarti meskipun pengelolaan pengembangan agroforestri berada di bawah ancaman tetapi dapat digunakan untuk mengeksploitasi peluang. Hasil perhitungan QSPM yaitu 4 strategi pengelolaan agrofoestry alternatif di HKm. Desain teknis agroforestri masih terfokus pada pertanian dan tanaman perkebunan, belum dikombinasi dengan tanaman kehutanan, sehingga strata tumbuhannya belum terbentuk dengan baik.
\end{abstract}

Kata Kunci : Agroforestri, Hutan Kemasyarakatan, SWOT, QSPM

Abstract

Agroforestry is a land use system that aims to sustain or increase total yields sustainably. Community Forest Utilization Permit (IUPHKm) is a business permit granted to local community groups to utilize forests in protected forest areas and / or production forest areas. HKm management for the community in the Melinani sub-district was carried out based on the technical design of agroforestry made by BPSKL in the Maluku and Papua regions. The research objectives are: (1) Knowing the economic, social and cultural and ecological characteristics of the Melinani community in utilizing Hkm; (2) Determine strategies and priorities for developing agroforestry systems and (3) Analyze the factors that determine the effectiveness of farmers' work. Multiple regression analysis is used in this research. For the determination of agroforestry development strategies used SWOT analysis and priority setting that must be carried out using the QSPM method. The results of the regression analysis indicate that the level of education and distance from residence have an impact on the development of agroforestry. The SWOT analysis is in the quadrant I. This means that even though the management of agroforestry development is under threat, it can be used to exploit opportunities. The results of QSPM calculations are 4 alternative agrofoestry management strategies in $\mathrm{HKm}$. The technical design of agroforestry is still focused on agriculture and plantation crops, not yet combined with forestry plants, so the strata of the plant have not been well formed.

Keywords: Agroforestry, Community Forestry,SWOT, QSPM

DOI:10.30598/jhppk.2018.2.1.70

ISSN ONLINE : 2621-8798

Page 70 


\section{PENDAHULUAN}

Konsep Pembangunan Hutan

Berbasis Masyarakat (PHBM) merupakan konsep pembangunan hutan yang diharapkan dapat mengakomodir kebutuhan dan kesejahteraan masyarakat di sekitar hutan. Salah satu bentuk pembangunan hutan berbasis masyarakat adalah hutan kemasyarakatan. Upaya pemerintah dalam menanggulangi kerusakan hutan dengan memberdayakan masyarakat di dalam dan sekitar kawasan hutan dilakukan melalui program hutan kemasyarakatan. Program ini ditujukan untuk memberikan kepastian kepada masyarakat dalam melakukan pengelolaan dan pemanfaatan sumber daya hutan dengan mementingkan kesejahteraan masyarakat dan kelestarian hutan sehingga fungsi pokok dari hutan tidak terganggu. Izin Usaha Pemanfaataan Hutan Kemasyarakatan (IUPHKm) adalah izin usaha yang diberikan kepada kelompok atau gabungan kelompok masyarakat setempat untuk memanfaatkan hutan pada kawasan hutan lindung dan atau hutan produksi.

Keputusan Gubernur Maluku No. 134 dan 135 Tahun 2015 Tanggal 10 Juni 2015 telah memberikan IUPHKm kepada Kelompok Tani Homa Ita Pano seluas \pm 700 Ha dan Kelompok Tani Latu seluas \pm 500 Ha pada Kawasan Hutan Produksi Terbatas di Dusun Melinani, Desa Manusela, Kecamatan Seram Utara, Kabupaten Maluku Tengah. Dengan terbitnya IUPHKm ini memberikan hak kepada masyarakat atau kelompok untuk memanfaatkan kawasan hutan dalam bentuk hasil hutan kayu dan bukan kayu. Aktivitasnya mencakup pembibitan, penanaman, pemeliharaan, pemanenan, pengolahan, dan pemasaran berdasarkan asas kelestarian hutan, sosial dan lingkungan dan/atau dalam bentuk pemanfaatan (jasa ekowisata, jasa keanekaragaman hayati, jasa penyerapan/ penyimpanan karbon). Berdasarkan Keputusan Gubernur tersebut Balai Perhutanan Sosial dan Kemitraan Lingkungan Wilayah Maluku Papua menyusun Rancangan Teknis Kegiatan Agroforestri pada masing-masing IUPHKm sebagai acuan pelaksanaan agroforestri di lapangan yang sesuai dengan kaidah teknis dan tepat guna baik dari aspek biofisik maupun sosial, serta ekonomi dan budaya wilayah setempat.

Keberhasilan pelaksanaan agroforestri dalam wilayah IUPHKm ini dipengaruhi oleh beberapa faktor yang perlu dikaji dan dianalisis sehingga menjadi alasan pentingnya dilakukan penelitian ini. Kajian yang diperlukan adalah untuk mengetahui karakteristik ekonomi, sosial dan budaya serta ekologi masyarakat dusun Melinani dalam pemanfaatan $\mathrm{Hkm}$; Menentukan strategi dan prioritas pengembangan sistem agroforestri berdasarkan rancangan teknis agroforestri IUPHKm dan Menganalisis 
faktor-faktor yang menentukan efektivitas

\section{METODE PENELITIAN}

\section{Lokasi dan Waktu Penelitian}

Penelitian dilaksanakan pada lokasi IUPHKm di Dusun Melinani, Desa

\section{Metode Pengumpulan Data}

Pemilihan sampel lokasi penelitian dilakukan dengan metode purposive sampling, keterwakilan dari masyarakat yakni Kelompok Tani Homa Ita Pano dan Kelompok Tani Latu yang terlibat langsung dalam kegiatan pemanfaatan $\mathrm{HKm}$ dan merupakan informan kunci yang dianggap memiliki kompetensi. Jenis data yang dikumpulkan dalam penelitian adalah data primer melalui interview respondens dan data sekunder melalui berbagai sumber yang didapat untuk menunjang penelitian seperti dari pemerintah desa, kecamatan, kota/kabupaten dan propinsi data sekunder. Bentuknya dapat berupa keadaan umum lokasi penelitian, dokumen-dokumen resmi (Rancangan teknis agroforestri) dan data yang berkaitan dengan $\mathrm{HKm}$ Dusun Melinani serta keadaan masyarakat. Pengumpulan data diperoleh dengan cara atau pengamatan langsung terhadap kelompok tani yang terlibat dalam pengelolaan dan pemanfaatan $\mathrm{HKm}$. Kemudian dilakukan wawancara dengan penggunanaan lembaran kuesioner. Wawancara dilakukan dengan pola komunikasi individu dan FGD. Analisis kerja dari pada petani.

Manusela Kecamatan Seram Barat Kabupaten Maluku Tengah.

faktor-faktor yang mempengaruhi pengelolaan agroforestry dilakukan berdasarkan pendekatan analisis regresi sederhana. Analisis ini diperoleh dari karakteristik respondens yang merupakan anggota kelompok tani yang terlibat langsung dalam aktivitas pengelolaan agroforestry pada HKm. Karakteristik respondens yang diukur yaitu: tingkat pendidikan, jumlah anggota keluarga, umur, jarak lahan dari rumah dan pendapatan respondens.

Untuk mengetahui faktor-faktor yang mempengaruhi pengelolaan agroforestri digunakan analisis kuantitaif dengan menggunakan rumus sebagai berikut :

$$
\mathrm{Y}=\mathrm{X} 1+\mathrm{X} 2+\mathrm{X} 3+\mathrm{X} 4+\mathrm{X} 5
$$

dimana :

$\mathrm{Y}=$ Waktu kerja efektif, $\mathrm{X} 1=$ Pendidikan respondens, $\mathrm{X} 2=$ Jumlah anggota keluarga respondens, $\mathrm{X} 3=$ Umur responden, X4 = Jarak lahan dari rumah, X5 $=$ Pendapatan respondens. Untuk menguji signifikansi pengaruh variabel-variabel terhadap variabel independen kemudian dilakukan analisis korelasi secara parsial untuk mengetahui bentuk dan kekuatan hubungan variabel independen dengan variabel dependen. Strategi pengembangan 
$\mathrm{HKm}$

di

lokasi

studi

dianalisis dengan menggunakan analisis SW

OT. Selanjutnya

disusun daftar prioritas yang harus diimplementasikan dengan metode QSPM (Quantitative Strategic Planning Matrix). Keunggulan QSPM adalah bahwa set strategi dapat dievaluasi secara bertahap atau bersama-sama. Sebagai contoh tingkat

\section{HASIL DAN PEMBAHASAN}

\section{Kondisi Ekologi Dusun Melinani}

Dusun Melinani memiliki potensi yang kaya dengan keanekaragaman jenis dan komposisi vegetasi baik di dalam maupun di korporasi dapat dievaluasi terlebih dulu, diikuti dengan tingkat strategi tingkat devisi, dan kemudian strategi tingkat fungsional. Tidak ada batasan untuk jumlah strategi yang dapat dievaluasi atau jumlah set stategi yang dapat dievaluasi pada satu saat menggunakan QSPM (David, 2001, Rangkut i, 2016).

Tabel 1. Jenis Vegetasi Utama di HKm Dusun Melinani

\begin{tabular}{ccc}
\hline No & Nama Lokal & Nama Latin \\
\hline 1. & Pala & Miristica fragfarans \\
2. & Cengkeh & Eugenia aromatica \\
3. & Pisang & Musa paradisiacal \\
4. & Pepaya & Carica papaya \\
5. & Jagung & Zea mays \\
6. & Ketela Pohon/singkong & Manihot utilissima \\
7. & Ubi Jalar/talas & Ipomoea batatas $L$ \\
8 & Samama/jabon merah & Antrhcephalus macrophyllus \\
9. & Salawaku & Albizia falcataria \\
10 & Kenari & Canarium indicum \\
11. & Durian & Durian zibethinus \\
\hline
\end{tabular}

Keragaman jenis dan komposisi vegetasi di HKm Dusun Melinani terdapat pada berbagai strata semai, sapihan tiang dan pohon. Tingkat semai dan sapihan didominasi oleh jenis samama, salawaku, kenari, tingkat tiang didominasi oleh samama dan kenari, pohon didominasi oleh tanaman durian, samama salawaku. Sedangkan jenis tanaman lain seperti talas, papaya, pisang merupakan jenis pengembangan dari program $\mathrm{HKm}$ yang luar wilayah Hutan Kemasyarakat. Adapun jenis - jenis tanaman yang ada di wilayah Hkm Dusun Melinani disajikan pada Tabel 1. 
(Pterocarpus indicus), Kayu Besi (Instia bijuga), Samama (Anthocephalus macrophyllus), dan Kayu Palaka. Dari berbagai jenis dan komposisi vegetasi yang belapis yang ada di wilayah HKm Dusun Melinani maupun yang ada di sekitar kawasan pemukiman penduduk dapat dimanfaatkan untuk memenuhi kebutuhan ekonomi sehari-hari baik untuk kebutuhan pangan maupun papan maupun obat-obatan. Pengelolaannya dilakukan dengan sangat sederhana berdasarkan pengetahuan local (local knowledge) masyarakat setempat. Misalnya : ubi kayu hanya direbus atau dibakar atau dibuat menjadi kripik yang enak dan gurih. Jenis fauna yang ada di lokasi studi: kus-kus (Ailurops $s p$ ), babi hutan (Sus scrofa). Selain pemanfaatan lahan HKm dengan system agroforestry yang diterapkan umumnya masyarakat juga mamanfaatkan pekarangan rumah sebagai

\section{Kondisi Ekonomi Masyarakat}

Kondisi ekonomi suatu masyarakat sangatlah tergantung dari mata pencaharian masyarakat itu sendiri. Sumber ekonomi masyarakat sebagian besar bersumber dari hasil agroforestry (baik yang ada di pekarangan, kebun/kabong, maupun di dusung). Hal ini dikarenakan sebagaian besar masyarakat bermata pencaharian sebagai petani yang kesehariannya mengelola dan memanfaatkan lahan untuk Kondisi Sosial dan Budaya Masyarakat lahan pertanian untuk sekedar menanam tanaman umur pendek, seperti keladi, singkong selain itu juga ada memanfaatkan lahan untuk memelihara ternak seperti ayam. Dari hasil pengamatan, masyarakat juga mempunyai kebun (kabong) yang letaknya agak jauh dari pemukiman penduduk dan biasanya di kebun kombinasi tanamanan yang ditanam lebih bervariasi dari pada di pekarangan rumah. Seperti tanaman umur panjang yaitu : cengkeh dan pala. Dapat dikatakan bahwa dalam pemanfaatan dan pengelolaan lahan milik pribadi masyarakat cenderung menentukan sendiri jenis, waktu, dan berapa banyak tanaman yang hendak ditanam di pekarangan, kebun maupun dusung. Hal ini dasarkan pada pengalaman maupun pengetahuan masyarakat terkait dengan musim menanam maupun jenis tanah untuk bertani.

bercocok tanam untuk memenuhi kebutuhan keluarga. Mengingat letak Dusun Melinani ini sangat jauh maka hasil pertanian yang diperoleh biasanya hanya untuk komsumsi keluarga atau ditukar (barter) dengan barang lain. Jika memungkinkan masyarakat untuk melakukan perjalanan ke kota kabupaten barulah mereka membawa hasil lahan untuk dijual dan kemudian membeli barang kebutuhan pokok lainnya.

Masyarakat lokal umumnya sangat kental dengan budaya serta kehidupan sosial 
yang tinggi dan memiliki hubungan yang saling mengenal satu dengan yang lain. Sehingga dalam melakukan suatu pekerjaan masyarakat lebih senang untuk melakukannya secara bersama - sama. Begitu pula halnya kehidupan masyarakat Dusun Melinani yang masih menerapkan hidup saling tolong-menolong/saling membantu dalam melaksanakan suatu pekerjaan. Tradisi dan kebiasaaan ini oleh masyarakat Maluku dikenal dengan nama budaya Masohi. Masohi atau gotong royong biasanya dilakukan oleh masyarakat dalam berbagai kegiatan misalnya dalam membantu sesama untuk menyelesaikan proses pembangaun rumah, mengerjakan kebun dan lain sebagainya. Salah satu bentuk kearifan lokal yang masih tetap dipertahankan juga selain Masohi: gotong royong yakni Sasi (Larangan). Sasi merupakan larangan untuk mengambil suatu hasil tanaman sebelum saatnya panen. Sasi bertujuan untuk menjaga kualitas dan kuantitas produksi secara kontinyu. Umumnya masyarakat dusun Melinani beragama Kristen protestan juga melaksanakan Sasi adat/gereja (Suatu aturan atau norma yang melarang masyarakat untuk mengambil hasil tanaman atau sumber daya alam tertentu dan dalam jangka waktu tertentu dimana aturan atau norma tersebut telah menyatu dengan kehidupan budaya mereka) dan sasi gereja ini dalam proses sasi buka dan sasi tutup semuanya dilakukan melalui lembaga dalam ibadah - ibadah Minggu sehingga masyarakat tahu bila mana saatnya buka sasi dan tutup sasi. Dalam bidang seni budaya, Dusun Melinani mempunyai suatu tarian keakraban yakni Tarian Kapata maku-maku. Dimana tarian ini diyakini berasal dari Nunusaku yang diwarisi oleh leluhur mereka secara turun temurun. Penari ini terdiri dari seorang beberapa personil yakni kapitan, mamiri, penari maku dan penabuh tifa. Kapitan bertugas untuk menyemangati penari dengan memberikan komando. Untuk sekarang ini biasanya tarian maku-maku oleh masyarakat dilakukan saat menyambut tamu dulunya dilakukan saat menyambut pasukan yang pulang berperang. Selain dari bidang seni adat lain yang masih ada di tengah-tengah masyarakat yakni Adat pisa/sou-sou yakni suatu tradisi untuk mencari tahu orang sakit atau sesuatu yang hilang. Misalnya jika seseorang kehilangan suatu barang maka ia akan datang seseorang untuk meminta tolong agar dapat mengetahui dimana barangnya yang hilang. Atau jika ada orang yang sakit maka dibawa ke orang untuk diobati secara tradisional. Masyarakat juga memiliki pengetahun lokal tentang jenisjenis tanaman yang dapat dimanfaatkan untuk menjadi obat-obatan tradisional, seperti: daun gatal biasanya dipakai untuk mengobati pegal-pegal dengan cara dipukulpukul dibagian yang sakit maka akan sembuh dan jenis tanaman obat tradisional 
lainnya yang didasarkan pada pengetahuan

\section{Pengelolaan dan Pemanfaatan HKm}

Agroforestri merupakan struktur hutan yang dibangun oleh masyarakat setempat dalam rangka diversifikasi produksi, melengkapi produksi bahan pangan yang dihasilkan untuk kebutuhan sendiri dari lahan tanaman semusim. Contoh-contoh diatas adalah hasil praktik tradisional pengelolaan hutan dan dikembangkan terus menerus oleh masyarakat setempat, yang merupakan hasil konsepsi, investasi dan perencanaan jangka panjang petani. Oleh sebab itu penentuan tanaman dan pola agroforestry dalam rangka pembangunan agroforestry sangat dipengaruhi oleh kebutuhan masyarakat dan tujuan pengembangan agroforestry. Berdasarkan pemilihan jenis tanaman dan desain penempatan tanaman pada lahan agroforestri di $\mathrm{HKm}$ sesuai Rancangan Teknis Agroforestri yang disusun oleh Balai PSKL Wilayah Maluku Papua maka dapat dikatakan bahwa ini merupakan penerapan model atau pola tanam yang dapat memanfaatkan lahan dengan maksimal dan juga memberikan hasil yang maksimal atau merupakan bentuk intensifikasi pertanian dan kehutanan pada lahan di HKm. Hal ini memberikan solusi bagi masyarakat petani agar dapat memanfaatkan lahan dengan maksimal dengan pola tanam dan jarak tanam yang teratur. Hal ini disebabkan karena selama ini masyarakat biasanya lokal.

menanam tanaman di dusung tidak mengikuti pola tanam tertentu misalnya tidak menggunakan jarak tanam karena tanaman hanya ditanam di sela-sela tanaman lain dalam satu areal. Namun kelemahan dari rancangan teknis tersebut adalah jenis tanaman yang digunakan masih berorientasi pada tanaman perkebunan dan pertanian sedangkan tanaman kehutanan belum diakomodir. Pemilihan jenis tanaman cengkeh (Eugenia aromatic) sebagai tanaman keras tidak dianjurkan dalam kegiatan agroforestri karena cengkeh merupakan tanaman alelopati yang dapat melepaskan senyawa bersifat toksik yang dapat mengganggu pertumbuhan tanaman di sekitarnya. Alternatif Jenis tanaman yang disarankan untuk mengganti tanaman cengkeh adalah kopi (Coffea $s p$ ) karena tanaman kopi dapat tumbuh dengan baik di dusun Melinani dan secara ekonomis hasilnya bisa memberikan tambahan pendapatan bagi anggota kelompok baik kelompok tani Latu maupun Homa Ita Pano. Secara garis besar dapat dikatakan bahwa pemilihan jenis tanaman berdasarkan rancangan teknis agroforestry di dusun Melinani belum dapat menghasilkan bentuk strata secara bertingkat yang secara ekologi berfungsi untuk mengurangi erosi dan banjir. Kelompok tani Latu dan kelompok tani Homa Ita Pano senantiasa berpedoman pada rancangan teknis yang telah dibuat. Hingga 
saat ini sudah hampir 2 tahun setelah dibentuknya kelompok tani dalam pengelolaan agroforestri di HKm setidaknya telah memberikan banyak pemahaman dan perubahan yang berdampak dimasyarakat. Misalnya adanya variasi jenis tanaman yang ada di HKm hingga adanya keberlanjutan panen dari musim-ke musim. Dengan demikian kebutuhan pangan masyarakat akan selalu terjamin. Di sisi lain masyarakat umumnya sebagian besar petani dapat menerapkan hal yang sama yakni pola tanam dan jenis tanaman lahan milik pribadi (dusung, kebun, maupun pekarangan) karena selama ini misalnya untuk tahapan pengelolaan lahan masih sepenuhnya diserahkan kepada alam dalam hal ini untuk masyarakat jarang sekali melakukan pemeliharaan secara rutin untuk tanaman yang ditanam maka dengan model agroforestry yang dilakukan.

Walaupun tidak bisa dipungkiri bahwa dalam jangka waktu 2 tahun ini jenis Karakteristik Sosial Masyarakat

Karakteristik sosial masyarakat sangat mempengaruhi aktivitas dalam pengelolaan dan pengembangan agroforestri dalam HKm baik tergantung faktor internal tanaman umur panjang seperti cengkeh dan pala belum dapat memberikan hasil yang optimal namun masyarakat tetap optimis untuk melakukan penanaman maupun pemeliharaan. Menurut masyarakat setempat tanaman/pohon berkayu merupakan tabungan jangka panjang yang sekali-kali jika dibutuhkan maka akan ditebang untuk memenuhi kebutuhan hidup masyarakat. Berdasarkan uraian diatas maka secara garis besar pengelolaan tanaman dengan sistem agroforestri adalah sebagai berikut : (1) Aspek jenis tanaman pada lahan agroforestri sangat beragam yakni terdiri dari tanaman keras (kayu) seperti salawaku, tanaman perkebunan seperti cengkeh, pala dan tanaman pangan seperti singkong, ubi jalar, (2)Aspek manfaat tidak langsung dari agroforestry yakni kelompok tanaman dapat dibagi menjadi kelompok tanaman jangka panjang, jangka menengah dan jangka pendek.

maupun faktor eksternal. Berbagai karakteristik tersebut antara lain tingkat pendidikan, pendapatan, umur, jumlah tanggungan anggota keluarga dan jarak lahan dari pemukiman (rumah).

\section{Karakteristik Respondens Berdasarkan Tingkat Pendidikan \\ Karakteristik respondens berdasarkan tingkat pendidikan disajikan pada Tabel 2.}


Tabel 2. Karakteristik Respondens Berdasarkan Tingkat Pendidikan

\begin{tabular}{ccccc}
\hline Tingkat & \multicolumn{2}{c}{ Kelompok Tani Latu } & \multicolumn{2}{c}{ Kelompok Tani Homa Ita Pano } \\
Pendidikan & Jumlah Respondens & Persentasi (\%) & Jumlah Respondens & Persentasi (\%) \\
\hline SD & 14 & 63,64 & 13 & 56,52 \\
SMP & 7 & 31,82 & 8 & 34,78 \\
SMA & 1 & 4,55 & 1 & 4,35 \\
S1 & - & 0,00 & 1 & 4,35 \\
Total & $\mathbf{2 2}$ & $\mathbf{1 0 0 , 0 0}$ & $\mathbf{2 3}$ & $\mathbf{1 0 0 , 0 0}$ \\
\hline
\end{tabular}

Berdasarkan Tabel 2. dapat dilihat bahwa umumnya tingkat pendidikan dari respondens sebagaian besar adalah SD sebanyak 27 orang dan yang terendah yakni sarjana (strata 1) yakni sebayak 1 orang. Tinggi rendahnya tingkat pendidikan seseorang sangat mempengaruhi pola pikir dalam pengelolaan dan pengembangan agroforestrI yang dilakukan. Seseorang dengan tingkat pendidikan strata 1 akan lebih mudah dan cepat memahami tentang maksud dan tujuan pengembangan agroforestri yang dilakukan oleh Balai PSKL jika dibandingkan dengan yang berpendidikan SD dan walaupun ada maka itu diperoleh dari pengalaman yang

\section{Karakteristik Respondens Berdasarkan Tingkat Pendapatan}

Selain tingkat pendidikan, karakteristik lain yakni tingkat pendapatan masyarakat juga sangat mempengaruhi aktivitas dalam pengelolaan dan pengembangan agroforestri. Seseorang dengan tingkat pendapatan yang rendah dijumpai. Karena pada umum penerapan teknologi pertanian oleh masyarakat di Dusun Melinani belumlah secanggih di wilayah lain. Masyarakat atau respondens dari kelompok tani masih menggunakan peralatan yang sangat sederhana seperti kapak, cangkul, linggis dalam mengelolah lahan. Keterlibatan seseorang dalam aktivitas pengembangan agroforestri yang dilakukan oleh Balai PSKL akan mempengaruhi pola pikirnya yang terdahulu walaupun untuk itu membutuhkan waktu yang lama. Karena tidak semua orang dapat menerima dengan mudah penerapan teknologi baru yang masuk dalam masyarakat.

tentunya akan berusaha lebih untuk bekerja demi memenuhi kebutuhan hidupnya. Umumnya tingkat pendapatan seseorang tergantung dari hasil pekerjaan atau mata pencahariannya. Mata pencaharian sebagian besar respondens yakni pertani. Untuk lebih jelas dapat dilihat pada Tabel 3. 
Tabel 3. Karakteristik Respondens Berdasarkan Tingkat Pendapatan

\begin{tabular}{ccccc}
\hline $\begin{array}{c}\text { Tingkat Pendapatan } \\
\text { (Rp/Bulan) }\end{array}$ & \multicolumn{2}{c}{ Kelompok Tani Latu } & \multicolumn{2}{c}{ Kelompok Tani Hotu Pano } \\
\cline { 2 - 5 } & $\begin{array}{c}\text { Jumlah } \\
\text { Respondens }\end{array}$ & $\begin{array}{c}\text { Persentasi } \\
(\boldsymbol{\%})\end{array}$ & $\begin{array}{c}\text { Jumlah } \\
\text { Respondens }\end{array}$ & $\begin{array}{c}\text { Persentasi } \\
(\mathbf{\%})\end{array}$ \\
\hline $500.000-1.000 .000$ & 3 & 13,64 & 6 & 26,09 \\
$>1.000 .000-1.500 .000$ & 5 & 22,73 & 3 & 13,04 \\
$>1.500 .000-2.000 .000$ & 10 & 45,45 & 7 & 30,43 \\
$>2.000 .000-2.500 .000$ & 3 & 13,64 & 5 & 21,74 \\
$>2.500 .000$ & 1 & 4,55 & 2 & 8,70 \\
\hline Total & $\mathbf{2 2}$ & $\mathbf{1 0 0 , 0 0}$ & $\mathbf{2 3}$ & $\mathbf{1 0 0 , 0 0}$ \\
\hline
\end{tabular}

Berdasarkan hasil pada Tabel 3. dapat dilihat bahwa pendapatan tertinggi respondens yakni diatas Rp. 2.500.000,/bulan hanya 1 orang pada Kelompok Tani Latu sedangkan kisaran pendapatan di atas Rp 1.500.000,- - Rp 2.000.000,-/bulan sebanyak 10 orang. Untuk Kelompok Tani Homa Ita Pano respondens dengan pendapatan tertinggi yakni diatas $\mathrm{Rp}$ 2.500.000,-/bulan sebanyak 2 orang sedangkan paling banyak respondens dengan pendapatan diatas Rp. 1.500.000,- - Rp. 2.000.000,-/bulan sebanyak 7 orang. Besarnya pendapatan yang diperoleh oleh Karakteristik Respondens Berdasarkan Tingkat Umur

Tingkat umur seseorang turut mempengaruhi aktivitas maupun produktifitas dalam melakukan pengelolaan lahan agroforestri di HKm. Tingkat umur respondens per bulan biasa dari tanaman umur panjang seperti cengkeh dan pala yang ketika musim panen hasilnya dijual. Karena pada umumnya masyarakat Dusun Melinani pengelolahan lahan dan hasilnya hanya untuk memenuhi kebutuhan seharihari. Hal ini dilakukan karena jauhnya jarak ke pasar ibu kota kecamatan (Wahai) sekitar $2 \mathrm{~km}$ maupun kabupaten (Masohi) sekitar $200 \mathrm{~km}$. Jauhnya jarak ini mempengaruhi respondens untuk mendistribusikan hasil lahannya ke kota sehingga umumnya mereka hanya mengkomsumsinya sendiri atau melakukan barter.

juga turut mempengaruhi proses pengambilan keputusan/kebijakan maupun penyerapan teknologi dan inovasi yang dikembangkan. Adapun karakteristik respondens berdasarkan tingkat umur disajikan pada Tabel 4.

Tabel 4. Karakteristik Respondens Berdasarkan Tingkat Umur

\begin{tabular}{ccccc}
\hline \multirow{2}{*}{$\begin{array}{c}\text { Tingkat Umur } \\
\text { (Tahun) }\end{array}$} & \multicolumn{2}{c}{ Kelompok Tani Latu } & \multicolumn{2}{c}{ Kelompok Tani Homa Ita Pano } \\
\cline { 2 - 5 } & $\begin{array}{c}\text { Jumlah } \\
\text { Respondens }\end{array}$ & $\begin{array}{c}\text { Persentasi } \\
(\boldsymbol{\%})\end{array}$ & $\begin{array}{c}\text { Jumlah } \\
\text { Respondens }\end{array}$ & Persentasi (\%) \\
\hline $20-30$ & 3 & 13,64 & - & 0,00 \\
$31-40$ & 5 & 22,73 & 8 & 34,78 \\
$41-50$ & 12 & 54,55 & 13 & 56,52 \\
$51-60$ & 2 & 9,09 & 1 & 4,35 \\
$61-70$ & - & 0,00 & 1 & 4,35 \\
\hline Total & $\mathbf{2 2}$ & $\mathbf{1 0 0 , 0 0}$ & $\mathbf{2 3}$ & $\mathbf{1 0 0 , 0 0}$ \\
\hline
\end{tabular}


Dari Tabel 4. dapat dilihat bahwa umumnya respondens berumur 41 - 50 tahun yang paling dominan pada kedua kelompok tani. Usia ini merupakan usia produktif dimana seseorang sangat sibuk dengan rutinitas pekerjaan sehari-hari untuk memenuhi kebutuhan hidupnya. Karena pada usia ini seseorang telah menikah dan memiliki tanggung-jawab untuk menghidupi keluarganya sehingga pada usia ini respondens baik dari Kelompok Tani Latu maupun Kelompok Tani Homa Ita Pano yang terlibat langsung dalam kegiatan pengembangan agroforestri sangat aktif baik

dari kegiatan persiapan lahan, penanaman hingga pemeliharaan.

\section{Karakteristik Respondens Berdasarkan Jumlah Anggota Keluarga}

Anggota keluarga dapat dikatakan sebagai suatu modal dalam melakukan suatu usaha atau pekerjaan. Karena anggota keluarga merupakan tenaga kerja internal dalam keluarga yang dapat membantu menyelesaikan pekerjaan-pekerjaan keseharian. Demikian pula halnya dengan keterlibatan anggota keluarga dalam kegiatan pengembangan agroforestri di HKm. Karakeristik responden berdasarkan jumlah anggota keluarga disajikan pada Tabel 5.

Tabel 5. Karakteristik Responden Berdasarkan Jumlah Anggota Keluarga

\begin{tabular}{ccccc}
\hline $\begin{array}{c}\text { Jumlah } \\
\text { Tanggungan } \\
\text { (Orang) }\end{array}$ & $\begin{array}{c}\text { Kelompok Tani Latu } \\
\text { Jumlah } \\
\text { Respondens }\end{array}$ & $\begin{array}{c}\text { Persentasi } \\
(\boldsymbol{\%})\end{array}$ & $\begin{array}{c}\text { Kelompok Tani Homa Ita Pano } \\
\text { Jumlah } \\
\text { Respondens }\end{array}$ & \begin{tabular}{c} 
Persentasi (\%) \\
\hline$\leq 1$
\end{tabular} \\
\hline 2 & - & 0,00 & - & 0,00 \\
3 & 5 & 0,00 & 3 & 13,04 \\
4 & 8 & 22,73 & 5 & 21,74 \\
$\geq 5$ & 9 & 36,36 & 8 & 34,78 \\
\hline Total & $\mathbf{2 2}$ & 40,91 & 7 & 30,43 \\
\hline
\end{tabular}

Berdasarkan Tabel 5. dapat dilihat bahwa untuk Kelompok Tani Latu respondens dengan jumlah anggota keluarga yang merupakan tanggungan kepala keluarga $\geq 5$ orang adalah yang paling banyak yaitu sebanyak 9 respondens dan yang paling sedikit adalah tanggungan 3 orang dengan 5 respondens. Sedangkan untuk Kelompok Tani Homa Ita Pano tanggungan terbesar yakni 4 orang sebanyak 8 renspondens dan yang paling sedikit yaitu 2 orang dengan 3 respondens. Anggota kelompok yang mempunyai tanggungan lebih banyak tentunya akan berusaha bekerja lebih giat bekerja demi memenuhi kebutuhan anggota keluarga yang menjadi tanggungannya. Selain kepala keluarga termasuk dalam anggota kelompok tani biasanya masyarakat juga memasukan anggota keluarga lain seperti anak maupun istri agar saat bekerja mereka dapat saling membantu dengan anggota keluarga lainnya. Jumlah anggota keluarga dan jenis kelamin dalam suatu keluarga ini juga sangat 
mempengaruhi kapasitas dan jenis pekerjaan yang dilakukan oleh seseorang dalam pengelolaan dan pengambangan agrogorestri di HKm.

\section{Karakteristik Respondens Berdasarkan Jarak Lahan HKm dari Rumah}

Jarak lahan dari pemukiman berpengaruh terhadap waktu tempuh ke tempat bekerja. Begitu pula halnya dengan jenis tanaman yang ditanam di lahan turut dipengaruhi oleh jarak dari pemukiman, misalnya untuk tanaman umur pendek (hortikultura) biasanya ditanam di pekarangan maupun kebun sedangkan tanaman umur panjang, tanaman berkayu ditanam di dusung yang letaknya agak jauh. Semakin dekat jarak dan waktu tempuh juga akan mempengaruhi pengawasan dan aktivitas dalam kegiatan agroforestri. Misalnya pada pekarangan rumah biasa pemilik setiap hari dapat bekerja dan melakukan aktivitas seperti mencabut rumput liana sedangkan kalau jarak yang jauh maka respondens hanya sewaktu-waktu ke dusung misalnya dalam seminggu 2-3 kali atau jika musim panen tiba. Karakteristik respondens berdasarkan jarak lahan HKm dari rumah disajikan pada Tabel 6.

Tabel 6. Karakteristik Respondens Berdasarkan Jarak Lahan HKm dari Rumah

\begin{tabular}{ccccc}
\hline $\begin{array}{c}\text { Jarak Lahan HKm } \\
\text { dari Rumah }\end{array}$ & $\begin{array}{c}\text { Kelompok Tani Latu } \\
\text { Jumlah } \\
\text { Respondens }\end{array}$ & $\begin{array}{c}\text { Persentasi } \\
(\mathbf{\%})\end{array}$ & $\begin{array}{c}\text { Kelompok Tani Homa Ita Pano } \\
\text { Jumlah } \\
\text { Respondens }\end{array}$ & \begin{tabular}{c} 
Persentasi (\%) \\
\hline$\leq 1$
\end{tabular} \\
$>1-2$ & 20 & 9,09 & 0 & 0,00 \\
$>2-3$ & 0 & 90,91 & 0 & 0,00 \\
$>3-4$ & 0 & 0,00 & 2 & 8,70 \\
$\geq 4$ & 0 & 0,00 & 18 & 78,26 \\
Total & $\mathbf{2 2}$ & 0,00 & 3 & 13,04 \\
\hline & & $\mathbf{1 0 0 , 0 0}$ & $\mathbf{2 3}$ & $\mathbf{1 0 0 , 0 0}$ \\
\hline
\end{tabular}

Tabel 6. menunjukan bahwa pada Kelompok Tani Latu 90,91\% atau sebanyak 20 respondens memiliki lahan HKm berjarak $>1$ - $2 \mathrm{Km}$ dari rumah. Sedangkan untuk Kelompok Tani Homa Ita Pano 78,26\% atau sebanyak 18 respondens memiliki lahan $\mathrm{HKm}$ dengan jarak >3 - $4 \mathrm{Km}$ dari rumah. Hal ini menunjukkan bahwa rata-rata jarak lahan HKm pada Kelompok Tani Homa Ita Pano lebih jauh jaraknya dari pemukiman di Dusun Melinani dibanding dengan Kelompok Tani Latu. Kondisi ini tentunya akan berpengaruh pada jumlah waktu bekerja pada masing-masing kelompok. Umumnya sebelum berangkat ke lokasi $\mathrm{HKm}$ para anggota kelompok tani ini berkumpul di suatu tempat barulah mereka sama-sama ke HKm agar nantinya ketika bekerja pengelola lahan mereka juga akan sama-sama bekerja. Waktu berangkat kerja biasa pagi sekitar pukul 07.00 WIT dan pulang sekitar jam 17.00 WIT, hal ini juga tergantung dari topografi Dusun Melinani yang merupakan lereng. Tetapi jika ada petugas yang datang maka mereka harus 
menunggu petugas untuk bersama-samap ke HKm atau sebagian sudah terlebih dahulu.

\section{Karakteristik Respondens Berdasarkan} Jumlah Waktu Kerja

Jumlah waktu bekerja masingmasing anggota kelompok tani pada kegiatan agroforestri di lokasi HKm tentunya akan berbeda satu dengan yang lain. Hal ini akan dipengaruhi oleh berbagai faktor seperti umur seseorang, pendapatan yang diperoleh saat ini, jarak lokasi tempat bekerja, pendidikan seseorang, ada tidaknya pekerjaan sampingan dan juga jumlah anggota keluarga yang menjadi tanggungannya. Karakeristik responden berdasarkan jumlah waktu kerja disajikan pada Tabel 7.

Tabel 7. Karakteristik Respondens Berdasarkan Jumlah Waktu Kerja

\begin{tabular}{|c|c|c|c|c|}
\hline \multirow{2}{*}{$\begin{array}{c}\text { Jumlah Waktu } \\
\text { Kerja } \\
\text { (Jam/Hari) }\end{array}$} & \multicolumn{2}{|c|}{ Kelompok Tani Latu } & \multicolumn{2}{|c|}{ Kelompok Tani Homa Ita Pano } \\
\hline & $\begin{array}{c}\text { Jumlah } \\
\text { Respondens }\end{array}$ & $\begin{array}{c}\text { Persentasi } \\
(\%)\end{array}$ & $\begin{array}{c}\text { Jumlah } \\
\text { Respondens }\end{array}$ & Persentasi (\%) \\
\hline $1-2$ & 0 & 0,00 & 1 & 4,35 \\
\hline $3-4$ & 0 & 0,00 & 8 & 34,78 \\
\hline $5-6$ & 11 & 50,00 & 12 & 52,17 \\
\hline $7-8$ & 11 & 50,00 & 2 & 8,70 \\
\hline Total & 22 & 100,00 & 23 & 100,00 \\
\hline
\end{tabular}

Dari Tabel 7 menunjukkan bahwa pada Kelompok Tani Latu sebanyak 11 respondens atau 50\% memiliki waktu kerja 5 - 6 jam/hari dan sisanya sebanyak 11 respondens memiliki waktu kerja $7-8$ jam/hari. Sedangkan pada Kelompok Tani Homa Ita Pano 12 respondens atau sebesar $52,17 \%$ memiliki waktu kerja 5 - 6 jam/hari, 8 respondens $(34,78 \%)$ memiliki waktu kerja $3-4$ jam/hari, 2 respondens $(8,70 \%)$ dengan waktu kerja $7-8$ jam/hari dan 1 respondens (4,35\%) dengan waktu kerja 1 - 2 jam/hari. Berdasarkan kondisi tersebut dapat disimpulkan bahwa jumlah waktu kerja anggota Kelompok Tani Latu lebih banyak dibanding anggota Kelompok Tani Homa Ita Pano.

\section{Pengelolaan Agroforestri}

Fungsi manajemen sangatlah penting dalam pelaksanaan suatu program. Fungsi manajeman yang diperlukan yang dari aspek perencanaan (planning), organisasi (organisation), pelaksanaan (actualisation) dan pengawasan (controling) . Hal ini juga dilakukan dalam pengelolaan dan pengembangan agroforestry di $\mathrm{HKm}$ atas kerja sama pihak Balai PSKL, kelompok tani maupun pemerintah desa setempat. Agroforestry yang dilakukan bertujuan untuk dapat meningkatkan kesejahteraan masyarakat dalam memperbaiki keadaan lingkungan yang rusak dan berkelanjutan dengan memeliharanya. Program-program agroforestry diarahkan pada peningkatan dan pelestarian produktifitas sumberdaya yang 
akhirnya akan meningkatkan taraf hidup

Analisis $\quad$ Faktor-Faktor Yang

Mempengaruhi Pengelolaan Agroforestri

Kelompok Tani Homa Ita Pano

Untuk mengetahui faktor-faktor yang mempengaruhi pengelolaan agroforestri digunakan analisis kuantitatif dengan menggunakan rumus sebagai berikut :

$$
\mathrm{Y}=\mathrm{X} 1+\mathrm{X} 2+\mathrm{X} 3+\mathrm{X} 4+\mathrm{X} 5
$$

dimana :

$\mathrm{Y}=$ waktu kerja efektif, $\mathrm{X} 1=$ pendidikan responden, $\mathrm{X} 2=$ jumlah anggota keluarga responden, $\mathrm{X} 3=$ umur responden, $\mathrm{X} 4=$ Jarak dari rumah ke lokasi HKm, X5 = Pendapatan respondens

Hasil analisis regresi untuk setiap faktor yang mempengaruhi pengelolaan agroforestry untuk kelompok tani Homa Ita Pano sebagai berikut :

$$
\begin{gathered}
\mathrm{Y}=3,55+0,273 \mathrm{X} 1-0,281 \mathrm{X} 2+0,131 \mathrm{X} 3 \\
-0,204 \mathrm{X} 4-0,193 \mathrm{X} 5
\end{gathered}
$$

Untuk hasil uji regresi hubungan waktu kerja (Y) kelompok tani Homa Ita Pano dengan variable $\mathrm{X}$ yakni :

$$
\begin{gathered}
Y=2,64+0,006 X 1, Y=3,53-0,274 X 2, \\
Y=2,34+0,146 X 3, Y=2,79-0,070 X 4, \\
Y=3,01-0,132 X 5
\end{gathered}
$$

Dari hasil uji regresi menunjukkan variabel X1 (Tingkat Pendidikan) dan X4 (Jarak Lahan dari Rumah) memberikan pengaruh secara signifikan terhadap waktu kerja efektif kelompok tani sedangkan variabel X2 (Umur), X3 (Jumlah Anggota Keluarga), dan X5 (Pendapatan) tidak masyarakat (Silaya, 2004).

memberkan pengaruh yang yang signifikan terhadap waktu kerja efektif Kelompok Tani Homa Ita Pano.

\section{Kelompok Tani Latu}

Sedangkan hasil uji regresi hubungan antara waktu kerja (Y) kelompok Latu dengan variabel $\mathrm{X}$ yakni :

$$
\mathrm{Y}=2,66-0,020 \mathrm{X} 1+0,133 \mathrm{X} 2-
$$

$0,353 \mathrm{X} 3+0,389 \mathrm{X} 4-0,191 \mathrm{X} 5$

Dengan hasil uji setiap varabel $X$ adalah sebagai berikut :

$$
\begin{gathered}
Y=3,50+0,000 X 1, Y=3,17+0,098 X 2, \\
Y=4,05-0,301 X 3, Y=3,50+0,000 X 4, \\
Y=3,74-0,089 X 5
\end{gathered}
$$

Dari hasil uji regresi menunjukkan variabel X1 (Tingkat Pendidikan) dan X4 (Jarak Lahan dari Rumah) berpengaruh secara signifikan terhadap waktu kerja efektif anggota kelompok tani, sedangkan variabel X2 (Umur), X3 (Jumlah Anggota Keluarga) dan X5 (Pendapatan) tidak berpengaruh secara signfikan terhadap waktu kerja efektif kelompok Latu.

Dari hasil uji regresi dari berbagai variable $\mathrm{X}$, pendidikan dan jarak memberikan pengaruh yang signifikan terhadap waktu kerja efektif kelompok tani Latu dan Homa Ita Pano. Hal ini dapat dijelaskan bahwa jika ditinjau dari tingkat pendidikan dari kedua kelompok, sebagian besar atau dominan mempunyai tingkat pendidikan adalah SD bahkan ada yang tidak sekolah sehingga pola pikir mereka dalam pengelolaan agroforestri 
tentunya sangat terbatas. Kemudian untuk jarak lahan dari rumah atau tempat tinggal, kelompok tani Latu lebih jauh jika dibandingan dengan kelompok tani Hatu Ita Pano dengan demikian waktu kerja kedua kelompok dari segi kuantitas sangat berbeda dan tentunya mempengaruhi kinerja secara keseluruhan. Sedangkan ketiga variable lainnya yakni jumlah anggota keluarga,

\section{Strategi Pengembangan Agroforestri}

\section{(1) Analisis SWOT}

Analisis SWOT didasarkan pada logika yang dapat memaksimalkan kekuatan (Strengths) dan peluang (Opportunities) namun secara bersamaan dapat meminimalkan kelemahan (Weaknesses) dan ancaman (Threats). Dengan menggunakan matriks internal dan eksternal maka diberikan bobot dan rating pada parameter umur dan pendapatan umumnya tidak jauh berbeda satu dengan yang lain sehingga tidak mempengaruhi waktu kerja efektif dari masing-masing kelompok tani. Kondisi ini secara umum tidak berbeda jauh dari penelitian Sahureka (2009) tentang Pengelolaan dan Pengembangan Hutan Rakyat di desa Soya dan desa Tawiri, Kota Ambon

yang telah ditentukan, sehingga akan diperoleh nilai (skor). Nilai ini yang akan memberikan arahan tentang prospek ke depan untuk pengembangan agroforestri guna memperoleh konsep strategis pengembangan agroforestry. Hasil penetapan skor untuk Faktor Strategis Internal dan Eksternal disajikan pada Tabel 8.

Tabel 8. Faktor Strategis Internal dan Eksternal

\begin{tabular}{|c|c|c|c|}
\hline Faktor Dimensi Internal & Bobot & Rating & Skor \\
\hline \multicolumn{4}{|l|}{ Kekuatan (S) } \\
\hline $\begin{array}{l}\text { 1. Keragaman jenis vegetasi dan hasil dalam lahan } \\
\text { agroforestri }\end{array}$ & 0,1387 & 3,10 & 0,4299 \\
\hline Adanya pembentukan kelompok tani & 0,1253 & 3,05 & 0,3821 \\
\hline $\begin{array}{l}\text { 3. Masyarakat sangat tergantung pada hasil } \\
\text { agroforestri }\end{array}$ & 0,1400 & 3,75 & 0,5250 \\
\hline $\begin{array}{l}\text { 4. Penerapan teknologi modern dalam kegiatan } \\
\text { agroforestri : peralatan }\end{array}$ & 0,1030 & 3,25 & 0,3347 \\
\hline $\begin{array}{l}\text { 5. Masyarakat masih mempertahankan tradisi dan } \\
\text { budaya setempat dalam pengelolaan agroforestri }\end{array}$ & 0,1239 & 3,20 & 0,3964 \\
\hline Adanya rancangan teknis pengelolaan agroforestri & 0,1189 & $\begin{array}{r}3,150,42 \\
2,4426\end{array}$ & 0,3745 \\
\hline Faktor Dimensi Internal & Bobot & Rating & Skor \\
\hline \multicolumn{4}{|l|}{ Kelemahan (W) } \\
\hline $\begin{array}{l}\text { 1. Belum adanya pemanfaatan lahan HKm secara } \\
\text { optimal }\end{array}$ & 0,0529 & 1,45 & 0,0767 \\
\hline 2. Belum adanya rencana jangka panjang & 0.0325 & 1,35 & 0,0438 \\
\hline 3. Jarak lokasi yang jauh dari pemukiman & 0,0230 & 1,60 & 0,0368 \\
\hline 4. Aksesibilitas yang belum memadai & 0,0245 & ,20 & 0,0294 \\
\hline \multicolumn{4}{|c|}{0,1894} \\
\hline
\end{tabular}




\begin{tabular}{|c|c|c|c|}
\hline Faktor Dimensi Eksternal & Bobot & Rating & Skor \\
\hline \multicolumn{4}{|l|}{ Peluang (O) } \\
\hline Adanya campuran program pemerintah(BPSHL) & 0,0960 & 3,50 & 0,336 \\
\hline Adanya diversifikasi produk dan ektensifikasi lahan & 0,0705 & 3,25 & 0,2291 \\
\hline Keterlibatan kelompok tani dalam pengelolaan & 0,0603 & 2,87 & 0,1730 \\
\hline 4. Hasil-hasil agroforestry yang diminati oleh masyarakat & 0,0532 & 3,75 & 0,1995 \\
\hline 5. $\quad$ Adanya Rancangan teknis tahun 1 dan tahun 2 & 0,0325 & $\begin{array}{r}3,15 \\
1,0399\end{array}$ & 0,1023 \\
\hline Faktor Dimensi Eksternal & Bobot & Rating & Skor \\
\hline \multicolumn{4}{|l|}{ Ancaman (T) } \\
\hline 1. Alih fungsi lahan hutan & 0,0120 & 2,40 & 0,0288 \\
\hline 2. Ancaman kebakaran hutan saat musim kemarau & 0,0145 & 2,38 & 0,0345 \\
\hline 3. Masih minumnya informasi dan pasar & 0,0130 & 2,25 & 0,0292 \\
\hline 4. Hama dan penyakit yang menyerang pada tanaman & 0,0125 & 2,15 & 0,0268 \\
\hline 5. Produk-produk local yang kalah bersaing & 0,0450 & 2,35 & 0,1057 \\
\hline 6. Rendahnya Tingkat pendidikan masyarakat. & 0,0250 & 2,20 & 0,055 \\
\hline & \multicolumn{3}{|c|}{0,28} \\
\hline
\end{tabular}

Berdasarkan pengolahan data dari data kuisioner yang diberikan kepada 55 responden maka didapatkan besaran nilai dari masing-masing faktor internal dan eksternal adalah sebagai berikut:

Nilai matriks evaluasi faktor strategis internal :

Total Kekuatan - Total Kelemahan

$$
2,44-0,18=2,25
$$

Nilai matriks evaluasi faktor strategi eksternal :

$$
\begin{gathered}
\text { Total Peluang - Total Ancaman } \\
1,03-0,28=0,75
\end{gathered}
$$

Selanjutnya dari matriks analisis strategis kemudian nilainya dimasukan ke dalam diagram kuadrant. Hasil analisis kuadran menunjukkan bahwa posisi pengelolaan dan pengembangan agroforestry pada $\mathrm{HKm}$ berada pada kuadran I seperti disajikan pada Gambar 1 


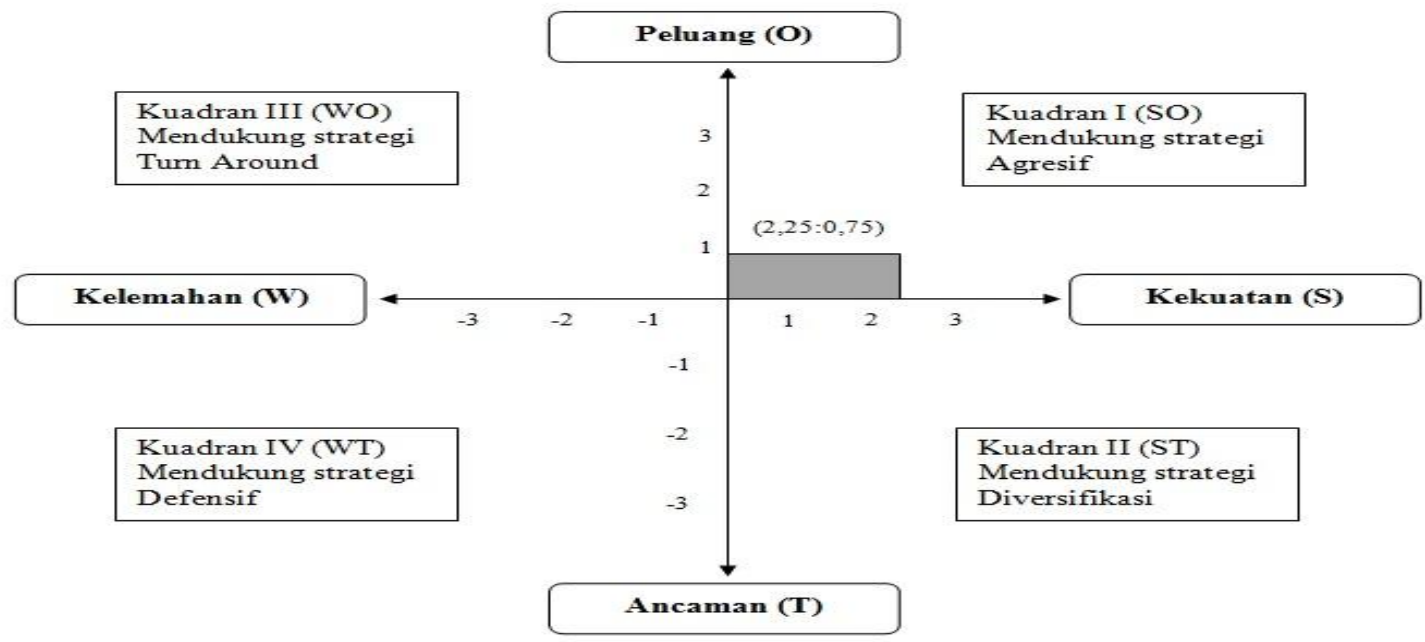

Gambar 1. Hasil Analisis SWOT pada Kuadran I.

Matriks kuadran menunjukan bahwa pada dasarnya manajemen pengelolaan mengalami ancaman namun masih memiliki kekuatan dari segi internal. Strategi yang

Prioritas Strategi Pengelolaan dan Pengembangan Agroforestri

Setelah melakukan analisis SWOT selanjutnya dilakukan evaluasi terhadap strategi dengan pendekatan QSPM. Tujuanny adalah untuk menentukan strategis prioritas yang mesti dilakukan agar pengelolaan agroforestry pada $\mathrm{HKm}$ dapat berjalan sesuai dengan tujuan yang ingin dicapai yang menentukan hubungan perlu dikembangan yakni menggunakan kekuatan yang ada untuk memanfaatkan peluang sehingga dapat mengatasi kelemahan yang ada.

keterkaitan antara strategi terhadap faktorfaktor kunci internal dan eksternal. Adapun strategi SO (Strengths Opportunities) yang dirumuskan dituangkan dalam Tabel 8 yang merupakan hasil perhitungan QSPM berdasarkan rangking dari nilai TAS yang paling besar ke nilai TAS yang paling kecil. Hasil perhitungan QSPM disajikan pada Tabel 9.

Tabel 9. Hasil Perhitungan Quantitative Strategic Planning Matrix (QSPM)

\begin{tabular}{clc}
\hline No & \multicolumn{1}{c}{ Alternatif strategi } & Nilai TAS \\
\hline 1. & $\begin{array}{l}\text { Pengelolaan agroforestry pada HKm bersama masyarakat secara } \\
\text { berkelanjutan }\end{array}$ & 4,46 \\
2. & Peningkatan ekonomi masyarakat melalui program pemberdayaan & 4,41 \\
3. & Keterlibatan unsur terkait dalam berbagai aspek manajeman & 4,25 \\
4. & Peningkatan sarana dan prasarana & 3,7 \\
\hline
\end{tabular}

Dari hasil analisis QSPM maka pengembangan agroforestry pada HKm dapat dijelaskan bahwa untuk terdapat 4 (empat) alternatif strategi yang 
dapat digunakan dengan menggunakan kekuatan (strength) untuk memanfaatkan peluang (opportunities) dapat dijelaskan sebagai berikut :

(1) Pengelolaan agroforestry pada $\mathrm{HKm}$ dilakukan bersama masyarakat secara berkelanjutan (NIlai TAS 4,46). Menurut Awang (2004), dalam pengelolaan sumber daya alam hutan (SDAH) oleh masyarakat, maka setiap masyarakat di dalam dan di sekitar hutan mempunyai kesempatan yang sama dan seluas-luasnya untuk :

- Mengembangkan system pengelolaan sumber daya hutan sesuai dengan pengetahuan tradisonal, praktek-praktek dan tradisi-tradisi serta institusi dan teknologi yang dimiliki.

- Melakukan pemantauan, pengawasan dan perlindungan atas kegiatankegiatan pengelolaan sumber daya alam hutan lahan serta dampakdampaknya

- Meningkatkan kemampuan dalam penyampaian informasi dan/atau laporan yang diperlukan untuk perlindungan dan pengamanan serta pengawasan hutan, melakukan pembinaan sumber daya hutan dan tanah kosong areal rehabilitasi dan areal bekas tebangan dan kegiatan pertambangan, dengan menggunakan dana yang disiapkan untuk itu dan sah menurut peraturan pemerintah melalui mendekatan RRA (Rapid Rural Appraisal) dan PRA (Participatory Rural Appraisal).

Masyarakat Dusun Melinani khususnya respondens memiliki interaksi langsung dengan hutan sebagai sumber daya alam yang dapat dikelola untuk kelangsungan hidup manusia maupun makhluk lain. Dengan demikian melalui program pengembangan Agrofsrestry di HKm sedianya memberikan ruang bagi masyarakat untuk berpartispasi bersama pemerintah mengelola hutan secara bersama sehingga akan memberikan hasil yang maksimum dan yang dapat memenuhi kebutuhan ekonomi, sosial budaya serta ekologi. Partisipasi atau keikutsertaan tersebut selalu diukur dari upaya-upaya memobilisasi tenaga kerja yakni kelompok tani Latu dan kelompok tani Homa Ita Pano mulai dari kegiatan perencanaan, pelaksanaan hingga monitoring. Artinya bahwa masyarakat dalam hal ini bukan sekedar sebagai objek pembangunan tetapi lebih dari itu masyarakat adalah subjek atau aktor dari pembangunan hutan umumnya dalam pengelolaan agroforestri pada HKm khususnya.

(2) Peningkatan ekonomi masyarakat melalui program pemberdayaan (nilai TAS 4,41) 
Pemberdayaan masyarakat diartikan sebagai upaya untuk memantau masyarakat dalam mengembangkan kemampuan sendiri sehingga bebas dan mampu mengatasi masalah dan mengambil keputusan sendiri secara mandiri. Dengan demikian pemberdayaan masyarakat dapat meningkatkan ekonomi masyarakat dalam hal ini kelompok tani untuk secara mandiri mengelola diri sendiri dan kelompoknya untuk memenuhi kebutuhannya dan mengatasi masalah di masa yang akan datang. Dengan adanya program pengembangan agroforestri yang didasarkan pada rancangan teknik maka jika hal tersebut dilakukan secara baik akan memberikan hasil yang maksimal baik dari segi kualitas maupun kuantitas sehingga muncul masyarakat kelompok tani yang kompetensi dan bertanggung jawab.

(3) Keterlibatan unsur terkait dalam berbagai aspek manajemen (Nilai TAS $4,25)$

Sebagaimana telah dibahas terlebih dahulu bahwa dalam manajemen suatu program ada berbagai aspek yang perlu diperhatikan yakni aspek teknik, kelembagaan, sosial, finansial, ekonomi dan aspek lingkungan yang mesti dilakukan secara matang mulai dari perencanaan (planning), penggorganisasi (Organization), pelaksanaan (actualisation) dan

Pengawasan (Controling).Dengan adanya keterkaitan dari berbagai aspek dalam pengelolaan agroforestri dalam HKm maka sudah tentu roda organisasi/kelompok tani akan berjalan dengan mulus dan saling berkesinambungan antara aspek yang satu dengan yang lainnya.

(4) Peningkatan sarana dan prasarana (Nilai TAS $=3,7)$

Keberadaan sarana dan sarana merupakan faktor yang strategis dalam pengembangan agroforestri. Untuk sementara ini berbagai upaya pembangunan telah dilakukan oleh Balai PSKL guna meningkatkan kinerja kelompok tani seperti pembuatan papan nama kegiatan, gubuk kerja dan pengadaan peralatan serta berbagai berbagaikan yang telah dilakukan. Hal ini akan mendorong kelompok tani untuk dapat bekerja dengan baik. Pengeloaan dan pengembangan agroforestri pada hutan kemasyarakatan di Dusun Melinani yang dilakukan oleh instansi pemerintah dalam hal ini Balai PSKL tidak semata-mata agar masyarakat memiliki akses dalam pengelolaan hutan bersama namun lebih dari itu agar dapat tercipta kesejahteraan masyarakat dalam mengelola potensi hutan yang ada sesuai dengan karakateristik masyarakatnya. Dalam 
implementasi program tentunya terdapat berbagai kendala yang mengakibatkan belum maksimalnya pencapaian output sesuai dengan target yang diharapkan maka hasil analisis SWOT dan QSPM dapat dijadikan sebagai rekomendasi dalam pengelolaan agroforestri pada HKm di Dusun Melinani adalah :

- Pemerintah Provinsi Maluku dalam hal ini pemerintah Kabupaten Maluku Tengah dan pihak terkait yakni Balai PSKL perlu membuat suatu regulasi tentang model agroforestri yang mesti diterapkan dalam pengelolaan Hutan.

- Penerapan model pengelolaan agroforestri pada $\mathrm{HKm}$ memberikan

\section{KESIMPULAN}

Tingkat pendidikan dan jarak lahan dari tempat tinggal atau rumah memberikan pengaruh secara signifikan terhadap waktu kerja efektif kelompok tani Homa Ita Pano dan kelompok tani Latu yang berdampak pada pengembangan agroforestri pada Izin Usaha Pemanfaatan Hutan Kemasyarakatan (IUPHKm) di Dusun Melinani.

Hasil analisis SWOT dengan nilai berada pada kuandran I menunjukkan bahwa walaupun manajemen pengelolaan pengembangan agroforestri mengalami ancaman seperti alih fungsi lahan, kebakaran hutan, hama dan penyakit, namun dengan kekuatan yang ada yakni keragaman jenis vegetasi, pembentukan kelompok, dampak yang positif dari aspek ekonomi, ekologi dan sosial budaya dengan demikian untuk dapat meningkatkan peran masyarakat (kelompok tani), meningkatkan pengetahuan dan akses masyarakat dalam pengelolaan hutan maka perlunya sosialisasi, penyuluhan, pendampingan.

Mendorong para stakeholder untuk melakukan berbagai kajian dan penelitian ilmiah terkait dengan aspek ekonomi, ekologi dan sosial budaya dalam pengelolaan agroforestri.

ketergantungan masyarakat terhadap hasil agroforestri, dapat digunakan untuk memanfaatkan peluang antara lain: campur tangan pemerintah dalam pengelolaan $\mathrm{HKm}$, diversifikasi produk, rancangan teknis pengelolaan agroforestry. Dengan demikian kelemahan yang ada seperti belum adanya pemanfaatan lahan secara optimal, belum adanya rencana jangka pendek, menengah maupun jangka panjang, jarak lahan yang jauh dari pemukiman serta aksesibilitas yang belum memadai dapat teratasi. Pemilihan jenis tanaman dalam rancangan teknis agroforestri masih terfokus pada tanaman pertanian dan perkebunan, belum dikombinasikan dengan tanaman kehutanan sehingga strata secara bertingkat tidak terbentuk. 


\section{DAFTAR PUSTAKA}

Awang, S. 2004. Dekontruksi Sosial Ekonomi Forestry. Reposisi Masyarakat dan Keadilan Lingkungan. Bayu Indra Grafika. PT Yogyakarta

David, L. 2001. Forest Manajemen to Sustain Ecological, Economi and Social Value, Fourth Edition London Rangkuti, F. 2016. Analisis SWOT : Teknik membedah Kasus Bisnis, Penerbit PT Gramedia Pustaka Utama Jakarta.
Sahureka, M. 2009. Pengelolaan dan Pengembangan Hutan Rakyat (Studi kasus di desa Soya dan desa Tawiri) Kota Ambon, Thesis Fakultas Program Studi Ilmu Kehutanan, Universitas Gadjah Mada Yogyakarta.

Silaya, Th.M. 2004. Kearifan Masyarakat Lokal dalam pengelolaan Sumber Daya Alam Hutan dan lingkungan di Kecamatan Taniwel Kabupaten Seram Bagian Barat. Thesis Fakultas Program Studi Ilmu Kehutanan, Universitas Gadjah Mada Yogyakarta. 